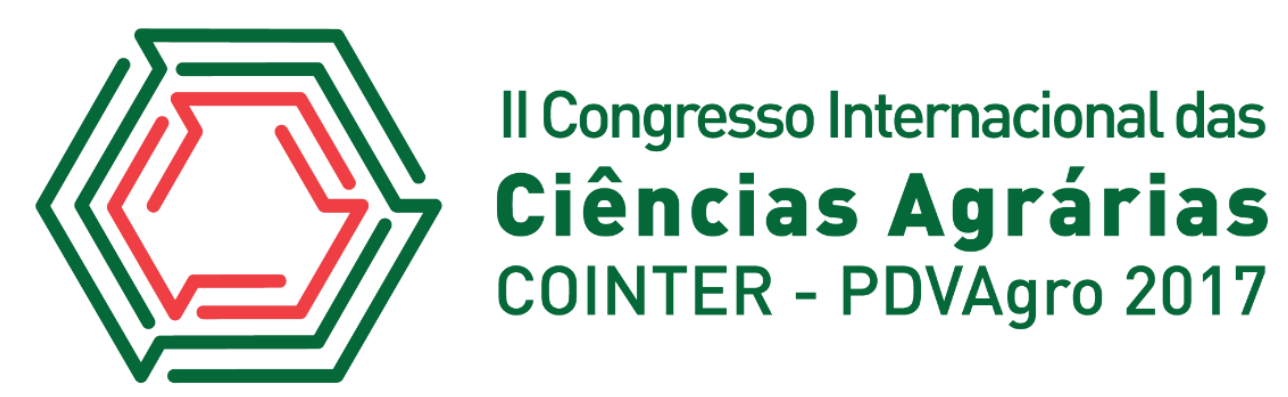

\title{
ANÁLISE DE CORRELAÇÃO EM FRUTOS DE JAMBO-VERMELHO (SYZYGIUM MALACCENSIS (L) MEER \& PERRY) EM CAPITÃO POÇO-PA
}

\author{
Apresentação: Pôster \\ Magda do Nascimento Farias ${ }^{1}$; Nayane da Silva Souza1 ${ }^{1}$ Larissa Jaina da Silva de Oliveira1; \\ Hemerson Doglas Campos Carvalho' ${ }^{1}$ : Marluce Reis Souza Santa Brigída ${ }^{2}$
}

\section{Introdução}

O jambo vermelho é uma planta de origem asiática, encontrado facilmente nas regiões norte, nordeste e regiões quentes do sudeste brasileiro apresentando copa densa que pode atingir até 15 metros de altura. O objetivo do presente trabalho foi analisar a correlação de frutos de jambo vermelho. A coleta dos frutos foi realizada no final do mês de agosto de 2016, final da época de frutificação na região, em quatro progênies de jambo vermelho, totalizando 200 frutos. As análises biométricas foram realizadas no laboratório de Ecofisiologia e Propagação de Plantas da Universidade Federal Rural da Amazônia, Campus Capitão Poço no mesmo dia de cada coleta a fim de evitar perdas e causar injúrias nos frutos. Os caracteres biométricos avaliados foram: peso do fruto (Pf), peso da polpa (Pp) e peso da semente (Ps) em gramas, comprimento do fruto (Cf) e diâmetro do fruto (Df) em mm e volume do fruto (Vf) em ml. Os dados foram submetidos ao teste de coeficiente de correlação não paramétrico de Spearman ( $\mathrm{r}_{\mathrm{s}}$ ) e o respectivo nível de significância $(\mathrm{p}<0,05)$ entre as variáveis. Os parâmetros que tiveram a maior correlação foram peso fruto e peso da polpa. Sendo possível, assim, afirmar que, o peso dos frutos tem influência direta sobre a massa de polpa obtida.

\section{Fundamentação Teórica}

O jambo vermelho Syzygium malaccensis pertencente à família Myrtaceae é uma planta de origem asiática e facilmente encontrado nas regiões norte, nordeste e regiões quentes do sudeste

\footnotetext{
${ }^{1}$ Estudantes de Agronomia da Universidade Federal Rural da Amazônia, Campus Capitão Poço, E-mail: magda.fariasagro@gmail.com

${ }^{2}$ Professora da Universidade Federal Rural da Amazônia, Campus Capitão Poço, E-mail: marluce.brigida@ufra.edu.br
} 
brasileiro. É uma planta com copa densa que pode atingir até 15 metros de altura (Cavalcante, 1996).

Segundo Donadio, 1998, os frutos são carnosos com rendimento de polpa de até $84 \%$ do fruto, ricos em vitaminas A, B1, B12, além de cálcio, ferro e fósforo (Lorenzi et al., 2006). O fruto é apreciado pelo seu sabor e aroma exóticos e possui propriedades aromáticas interessantes que o favorece como agente flavorizante em alimentos e bebidas (Augusta et al., 2010).

Há poucos estudos sobre a correlação dos caracteres físicos do jambo vermelho. Desse modo, se faz necessário o estudo mais criterioso sobre o assunto, uma vez que se trata de um fruto tradicionalmente utilizado por vários povos e culturas para fins medicinais, auxiliando no tratamento de diferentes doenças. A biometria dos frutos fornece informações para a conservação e exploração dos recursos de valor econômico, o que permite um incremento contínuo da busca racional e uso eficaz dos frutos (Gusmão et al., 2006). Buscou-se estimar a influência dos principais caracteres dos frutos de jambo vermelho sobre o rendimento de polpa, a partir da correlação entre essas variáveis obtidas pela biometria dos frutos.

\section{Metodologia}

O presente trabalho é de natureza quantitativa do tipo experimental desenvolvido no município de Capitão Poço-Pa, nordeste paraense, localizado entre as coordenadas geográficas de $1^{\circ} 44^{\prime} 47^{\prime \prime}$ S e 4703'57'W.

Os frutos de jambo foram coletados em 4 progênies diferentes, sendo 50 frutos em cada ponto, totalizando 200 frutos, dentro do perímetro urbano do município de Capitão Poço, nordeste paraense. Os frutos foram amostrados aleatoriamente. (Silva, et al., 2013). As coletas foram realizadas no final do mês de agosto de 2016, época de maior frutificação na região, sendo colhidos os frutos mais maduros. As análises biométricas foram realizadas no mesmo dia de cada coleta a fim de evitar perdas e causar injúrias nos frutos, no laboratório de Ecofisiologia e Propagação de Plantas da Universidade Federal Rural da Amazônia, Campus Capitão Poço.

Os caracteres biométricos avaliados foram: peso do fruto (Pf), peso da polpa (Pp) e peso da semente (Ps) em gramas, comprimento do fruto (Cf) e diâmetro do fruto (Df) em mm e volume do fruto (Vf) em ml. Nas análises laboratoriais utilizou-se paquímetro para mensurar o comprimento e diâmetro, balança semi-analítica para pesagem dos frutos e sementes, proveta de $2000 \mathrm{ml}$ para medir o volume. A massa da polpa foi calculada utilizando a expressão: $(M p=M f-M s)$ onde: ( $\mathrm{Mp}=$ Massa da polpa; $\mathrm{Mf}=$ Massa do fruto; Ms = Massa da semente). 
Os dados foram submetidos ao teste de coeficiente de correlação não paramétrico de Spearman $\left(\mathrm{r}_{\mathrm{S}}\right)$ e o respectivo nível de significância $(\mathrm{p}<0,05)$ entre as variáveis.

\section{Resultados e Discussões}

Os parâmetros analisados para os caracteres do jambo vermelho mostraram correlação positiva entre os dados com significância $(\mathrm{p}<.01)$ pelo teste t. Na tabela 1 é possível notar uma alta correlação principalmente entre o peso do fruto (PF) e o peso da polpa (PP), este efeito pode estar relacionado a diversos fatores como genético e ambiental. Em trabalho com pupunheira Moreira et al., (2016) encontraram resultados semelhantes para peso de fruto e rendimento de polpa.

Variável como volume do fruto apresentou pouca relevância com caracteres como peso do fruto, diâmetro e largura do fruto, porém com moderada relevância quando relacionado com o peso da polpa.

Para a amostra 2 (Tabela 2) a variável peso do fruto e peso da polpa obteve interação forte de 0,90 evidenciando que o peso do fruto é diretamente proporcional ao peso da polpa. Gusmão et al., 2006) em analise biométrica em frutos e endocarpos de murici, observaram que a polpa contribui com cerca de $73,63 \%$ do total do fruto, proporcionando maior rendimento de polpa. Esses resultados podem ter sido encontrados devido a influências climáticas, edáficas e nutritivas.

Tabela 1. Matriz de correlação para as variáveis da amostra 1 (VA): Peso do Fruto (g), Diâmetro do Fruto (mm), Diâmetro do Fruto (mm), Volume do Fruto (ml) e Peso de Polpa (g). Fonte: Própria

\begin{tabular}{cccccc}
\hline $\mathbf{V A} / \mathbf{V A}$ & $\mathbf{P F}$ & $\mathbf{C F}$ & $\mathbf{D F}$ & $\mathbf{V F}$ & $\mathbf{P P}$ \\
\hline $\mathbf{P F}$ & 1 & 0,34 & 0,38 & 0,75 & 0,87 \\
$\mathbf{C F}$ & $* *$ & 1 & 0,50 & 0,23 & 0,16 \\
$\mathbf{L F}$ & $* *$ & $* *$ & 1 & 0,17 & 0,30 \\
$\mathbf{V F}$ & $* *$ & $* *$ & $* *$ & 1 & 0,66 \\
$\mathbf{P P}$ & $* *$ & $* *$ & $* *$ & $* *$ & 1 \\
\hline
\end{tabular}

Para Botezelli et al., (2000) mesmo pert as plantas estão sujeitas a variações de temperat características químicas e físicas do solo, al ( $\mathrm{p}>=.05$ ). Tabela 2. Matriz de correlação para as variáveis da amostra 2 (VA): Peso do Fruto (g), Diâmetro do Fruto (mm), Diâmetro do Fruto (mm), Volume do Fruto (ml) e Peso de Polpa (g). Fonte: Própria

\begin{tabular}{cccccc}
\hline $\mathbf{V A} / \mathbf{V A}$ & $\mathbf{P F}$ & $\mathbf{C F}$ & $\mathbf{D F}$ & $\mathbf{V F}$ & $\mathbf{P P}$ \\
\hline $\mathbf{P F}$ & 1 & 0,40 & 0,81 & 0,87 & 0,90 \\
$\mathbf{C F}$ & $* *$ & 1 & 0,28 & 0,36 & 0,40 \\
$\mathbf{L F}$ & $* *$ & $* *$ & 1 & 0,72 & 0,75 \\
$\mathbf{V F}$ & $* *$ & $* *$ & $* *$ & 1 & 0,83 \\
$\mathbf{P P}$ & $* *$ & $* *$ & $* *$ & $* *$ & 1 \\
\hline
\end{tabular}

produtivos nos frutos. Para esta autora, esses fatores afetam positiva ou negativamente as culturas e acabam por ressaltar certos aspectos de sua composição genética, ou seja, o meio pode ser adequado ou não para expressão de determinadas características da planta. 
$\mathrm{Na}$ amostra 3 (Tabela 3) variáveis como peso do fruto e peso da polpa mostraram forte correlação $(0,93)$ bem como as variáveis volume do fruto e peso da polpa. Ferraz et al., (2014) fazendo análise biométrica de frutos de jamelão observaram alta correlação entre peso do fruto e rendimento de polpa. Essas variáveis têm grande importância em estudos, pois estas determinam o formato do fruto (Ataíde et al., 2012).

Tabela 3. Matriz de correlação para as variáveis da amostra 3 (VA): Peso do Fruto (g), Diâmetro do Fruto (mm), Diâmetro do Fruto (mm), Volume do Fruto (ml) e Peso de Polpa (g). Fonte: Própria

\begin{tabular}{cccccc}
\hline $\mathbf{V A} / \mathbf{V A}$ & $\mathbf{P F}$ & $\mathbf{C F}$ & $\mathbf{D F}$ & $\mathbf{V F}$ & $\mathbf{P P}$ \\
\hline $\mathbf{P F}$ & 1 & 0,40 & 0,68 & 0,81 & 0,93 \\
$\mathbf{C F}$ & $* *$ & 1 & 0,43 & 0,51 & 0,40 \\
$\mathbf{L F}$ & $* *$ & $* *$ & 1 & 0,75 & 0,64 \\
$\mathbf{V F}$ & $* *$ & $* *$ & $* *$ & 1 & 0,80 \\
$\mathbf{P P}$ & $* *$ & $* *$ & $* *$ & $* *$ & 1 \\
\hline
\end{tabular}

** significativo ao nível de $1 \%$ de probabilidade (p $<01)$; * significativo ao nível de $5 \%$ de probabilidade $(.01=<\mathrm{p}<.05)$; ns não significativo $(\mathrm{p}>=.05)$.
Tabela 4. Matriz de correlação para as variáveis da amostra 4 (VA): Peso do Fruto (g), Diâmetro do Fruto (mm), Diâmetro do Fruto (mm), Volume do Fruto (ml) e Peso de Polpa (g). Fonte: Própria

\begin{tabular}{cccccc}
\hline $\mathbf{V A} / \mathbf{V A}$ & $\mathbf{P F}$ & $\mathbf{C F}$ & $\mathbf{D F}$ & $\mathbf{V F}$ & $\mathbf{P P}$ \\
\hline $\mathbf{P F}$ & 1 & 0,68 & 0,76 & 0,42 & 0,94 \\
$\mathbf{C F}$ & $* *$ & 1 & 0,62 & 0,10 & 0,63 \\
$\mathbf{L F}$ & $* *$ & $* *$ & 1 & 0,44 & 0,72 \\
$\mathbf{V F}$ & $* *$ & $* *$ & $* *$ & 1 & 0,40 \\
$\mathbf{P P}$ & $* *$ & $* *$ & $* *$ & $* *$ & 1 \\
\hline
\end{tabular}

** significativo ao nível de $1 \%$ de probabilidade (p $<01)$; * significativo ao nível de $5 \%$ de probabilidade $(.01=<\mathrm{p}<.05)$; ns não significativo $(\mathrm{p}>=.05)$.

De acordo com as informações da Tabela 4, para todas as variáveis houve correlação positiva $(\mathrm{p}<0,01)$, sendo que os coeficientes mais relevantes foram encontrados nas interações: peso do fruto x peso da polpa [r] 0,94; peso do fruto x largura do fruto [r] 0,76 e largura do fruto x polpa do fruto $[\mathrm{r}] 0,72$.

Para Gusmão et al. (2006) a variação encontrada nas dimensões dos frutos de $B$. verbascifolia pode ser promovida por fatores ambientais, como a disponibilidade de água que parece ser um fator essencial para a produção de frutos carnosos.

\section{Conclusões}

Foram encontradas variabilidades morfológicas nas amostras de S. malaccensis para os caracteres dos frutos, de acordo com os dados biométricos, obtendo-se maior correlação de peso fruto e peso da polpa. Portanto, o peso dos frutos tem influência direta sobre a massa de polpa obtida.

\section{Referências}


ATAIDE, E. M.; OLIVEIRA, J. C.; RUGGIER, C. Florescimento e frutificação do maracujazeiro silvestre Passiflora setacea d. c. cultivado em Jaboticabal, SP. Revista Brasileira de Fruticultura, Jaboticabal - SP, v. 34, n. 2, p. 377-381, 2012.

AUGUSTA, I.M., RESENDE, J.M., BORGES, S.V., MAIA, M.C.A., COUTO, M.A.P.G. Caracterização física e química da casca e polpa de jambo vermelho (Syzygium malaccensis, (L.) Merryl \& Perry). Ciência e Tecnologia de Alimentos. v. 30, n. 4, p. 928-932, 2010.

BOTEZELli, L.; DAVIDE, A. C; MALAVASI, M. M. Características dos frutos e sementes de quatro procedências de Dipteryx alata vogel (baru). Cerne, v. 6, n. 1, p. 9-18, 2000.

CAVAlCANTE, P.B. Frutas comestíveis da Amazônia. 6.ed. Belém: CNPq/Museu Paraense Emílio Goeldi, 1996. 279p.

DONADIO, C.D.; NACHTGAL, J.C.; SACRAMENTO, C.K. Frutas exóticas. Jaboticabal: FUNEP, 1998. 279p.

FERRAZ, Y. T.; REIS, A. T. S.; SOUZA, N. da S. et al. Influência biométrica sobre o rendimento da polpa do jamelão (Syzygium jambolanum dc.) em Capitão Poço/Pa. Enciclopédia Biosfera, Goiânia, v.10, n.19; p. 1179-1187, 2014.

GUSMÃO, E.; VIEIRA, F. de. A.; FONSECA JÚNIOR, É. M. Biometria de frutos e endocarpos de murici (Byrsonima verbascifolia Rich. ex A. Juss.). Revista Cerne, Lavras, v. 12, n. 1, p. 8491, jan./mar. 2006.

LORENZI, H; BARCHER, L.; LACERDA, M.; SARTORI, S. Frutas brasileiras e exóticas cultivadas (de consumo in natura). São Paulo, Instituto Plantarum de Estudos da Flora, 2006, 572 p.

MOREIRA, W.K.O.; OLIVEIRA, S.S.; REIS, J.S.; PARAENSE, L. R. C. et al. Análise de correlação em frutos de pupunha (Bactris gasipaes KUNTH). Global Science and Technology, Rio Verde, v.09, n.03, p.106 - 115, set/dez. 2016.

SILVA, M. S. et al. Biometria de frutos e sementes de Melanoxylon brauna Schott (FABACEAE CAESALPINIOIDEAE). Cerne, Lavras, Volume 19, no: 3, p. 517-524, jul./set. 2013. 